Special Issue Nr. 43: Advertising Literacy. How Can Children and Adolescents Deal with Persuasive Messages in a Complex Media Environment?

Edited by Brigitte Naderer, Nils S. Borchers, Ruth Wendt, and Thorsten Naab

\title{
The Visual Self
}

\section{The Connection between Adolescents' Self-Presentation on Instagram and Their Ability to Recognize and Evaluate Advertising Content}

Claudia Riesmeyer (D), Pauline Sawatzki, and Amelie Hagleitner (D)

\begin{abstract}
This article analyzes adolescents' self-presentation on Instagram, the role influencers might play in such content, and adolescents' advertising literacy, defined as recognizing and evaluating advertising presented by influencers as well as using advertising knowledge. Based on 32 in-depth interviews and think-aloud protocols, this study identifies five types of self-presentation (staged, natural, covert, changed, and two-sided). Influencers were important benchmarks for almost all the adolescents interviewed; the participants each followed one or more influencers on Instagram and were inspired by the advertised products. Furthermore, they recognized influencers' commercial interests and presentation strategies. Their positive or negative evaluations of these strategies were linked to their self-presentation and ranged from approval to rejection. A negative evaluation of advertising did not automatically lead to a rejection of the implied advertising message. A discrepancy between the adolescents' knowledge and actions became clear when they admitted buying advertised products despite being critical of advertising or knowing which advertising mechanisms were being applied.
\end{abstract}

Das visuelle Ich. Der Zusammenhang zwischen der Selbstdarstellung Heranwachsender auf Instagram und ihrer Fähigkeit, Werbeinhalte zu erkennen und zu bewerten

\begin{abstract}
Zusammenfassung
Der Artikel analysiert die Selbstdarstellung Heranwachsender auf Instagram, die Rolle, die Influencer bei der Selbstdarstellung Heranwachsender spielen, und ihre Werbekompetenz, definiert als die Fähigkeit, die von Influencern präsentierte Werbung zu erkennen und zu bewerten. Auf der Grundlage von 32 Leitfadeninterviews und Think-Aloud-Protokollen identifiziert die Studie fünf Arten der Selbstdarstellung (inszenierte, natürliche, verdeckte, veränderte und zweiseitige Selbstdarstellung). Für fast alle befragten Heranwachsenden waren Influencer ein wichtiger Massstab und Orientierung: Sie folgten einem oder sogar mehreren Influencern auf Instagram und liessen sich von den beworbenen Produkten inspirieren. Darüber hinaus erkannten die Heranwachsenden das kommerzielle Interesse
\end{abstract}


und die Präsentationsstrategien von Influencern. Die positive oder negative Bewertung dieser Strategien war mit ihrer Selbstdarstellung verbunden und reichte von Ablehnung bis Zustimmung, wobei eine negative Bewertung der Werbung nicht automatisch zu einer Ablehnung der implizierten Werbebotschaft führte. Eine Diskrepanz zwischen dem Wissen der Heranwachsenden und ihrem Handeln wird deutlich, denn selbst wenn sie der Werbung kritisch gegenüberstanden oder wussten, welche Werbemechanismen verfolgt wurden, gaben sie zu, die von Influencern beworbene Produkte zu kaufen.

\section{Introduction}

Instagram is the most popular social network site among German adolescents aged between 12 and 19 years old. Of these, 64 percent use it regularly, while 52 percent use it daily and follow an average of 282 individual or organizational accounts (Feierabend et al. 2020, 31). Instagram has become an important social network site for identity performance (Boyd 2014) because adolescents can present themselves by posting pictures, following other accounts, and liking posts (Chua and Chang 2016; Dumas et al. 2017; Lee et al. 2015; Sheldon and Bryant 2016). Identity formation is a central development task in adolescence (Erikson 1959, 1968), and Instagram is thus a place to experiment with one's own identity and try out different ways of presenting it. For this self-presentation, social reference points and referent others are important. Initial studies have shown that peers act as role models for adolescents (Chua and Chang 2016; Yau and Reich 2018) and that parents set basic rules for using social network sites and communicate them to their children (Hudders and Cauberghe 2018; Livingstone and Helsper 2008).

However, Instagram is not only used for private communication but also by public figures and organizations pursuing commercial interests with their accounts.

"Instagram is the platform that is most used by opinion leaders (influencers), due to the sense of immediacy that is generated and because of its creation of communities" (Casalóa, Flavián, and Ibáñez-Sánchez 2018, 1).

Influencers often use professional and staged self-presentation to increase their number of followers and thus their opportunities for financial gain. Because of adolescents' intensive use of Instagram and the important role it plays for them, influencers can become new members of their networks (Geber and Hefner 2019) and may provide an orientation for adolescents' self-presentation (von Rotz and Tokarski 2020) because their self-presentation as an expression of their identity formation is "influenced by settings and the people in those settings" (Yau and Reich 2018, 197; Maccoby 1980). However, the role that influencers play in adolescents' self-presentation has hardly been investigated to date. 
Furthermore, adolescents need advertising literacy (Rozendaal et al. 2011), which develops in childhood and adolescence (Friestad and Wright 1994; Roedder John 1999; Rozendaal, Buijzen, and Valkenburg 2011) and is defined as conceptual and attitudinal advertising literacy as well as advertising literacy performance (knowledge, evaluation, and the retrieval of knowledge; Rozendaal et al. 2011). Since the self-presentation and general profile aesthetic of many influencers is characterized by sponsored content, recognition and the ability to distinguish paid and organic activities might add another layer to the conception of advertising literacy. However, advertising literacy enables adolescents

- to recognize advertising content (the identification of said paid content among that which is organic) and influencers' self-presentation as a possibly staged and commercial-interest-driven activity (influencers' Instagram use not only for selfbut also for brand marketing);

- to critically evaluate advertising content, influencers' self-presentation, and their commercial and persuasive interests; and

- to act according to their knowledge (knowledge transfer into action as regards one's own self-presentation as well as the orientation of their consumer decisions based on the influencers' recommendations).

An assumption could be that the more advertising-literate adolescents are, the more likely they are to recognize and evaluate influencers' self-presentation on Instagram as described above, on the one hand, and the advertised product, on the other hand, and to question and adapt their own self-presentation and consumer behavior accordingly. However, to our knowledge, studies that examine this assumption are seldom.

This article analyzes the link between adolescents' self-presentation on Instagram, the role influencers might play in such content (e.g., as role models), and the adolescents' advertising literacy in terms of their ability to recognize and evaluate influencers' self-presentation in general and advertising content within this self-presentation on Instagram and to act according to their advertising knowledge. Based on 32 in-depth interviews and think-aloud protocols with 14-17-year-old adolescents, the study emphasizes the importance of advertising literacy for the recognition and evaluation of advertising messages, on the one hand, and adolescents' (influenced) self-presentation, on the other. 


\section{Theoretical Framework}

\subsection{Adolescents' Self-Presentation on Instagram}

Self-presentation refers to the process through which individuals attempt to control the impressions that others form of them (Leary and Kowalski 1990). Since the impressions that people make regarding others influence how others perceive, evaluate, and treat them, people are interested in creating an impression that serves their interests (Goffman 1990; Leary and Kowalski 1990). This impression does not necessarily have to be positive but must at least be in line with their objectives. Instagram offers adolescents the possibility to present themselves and form their own identities (Chua and Chang 2016). This self-presentation is influenced by both the individual's goals and possibilities (Leary and Kowalski 1990) and the audience's characteristics (Rui and Stefanone 2013). Thus, self-presentation always occurs in a specific social context that is influenced by the expectations of referent others, for example, peers or influencers who also strive to create a certain image of themselves online.

Instagram as a social networking site has a graphic, image-based character (Grieve 2017; Sheldon and Bryant 2016). The visual characteristics of this social network predetermine adolescents' self-presentation (Dumas et al. 2017; Lee et al. 2015). Instagram provides adolescents with a platform to present themselves through posting pictures, following other accounts, and liking other posts (Chua and Chang 2016; Dumas et al. 2017; Lee et al. 2015; Sheldon and Bryant 2016). Therefore, Instagram is a place for them to perform and to experiment with their own identities (Boyd 2014) and to try out different ways of presenting them (Lup, Trub, and Rosenthal 2015; Sheldon and Bryant 2016).

Initial studies have shown that adolescents always try to show themselves in a positive way on Instagram, as desired by referent others (e.g., Siibak 2009). According to Yau and Reich $(2018,201)$, adolescents' self-presentation is based on three peer expectations regarding the need to appear to be interesting (e.g., showing no negative moments of one's life), likeable (e.g., receiving likes for one's published content), and attractive (e.g., looking good). While adolescents generally orient themselves toward these expectations, Yau and Reich (2018) also found evidence that they actively distance themselves from others to some extent, for example, by creating a second account on Instagram to share very personal pictures with only a small circle of friends. This form of self-presentation may also be due to a possible discrepancy between one's own expectations and those of referent others, which may nonetheless converge over time (Chua and Chang 2016). RQ 1 examines what form of selfpresentation is actually chosen by adolescents:

$R Q$ 1: How do adolescents reflect on their self-presentation on Instagram? 


\subsection{Influencers and Their Commercial Interests}

Influencers are social network site users with a wide reach and expertise in their field (de Veirman, Hudders, and Nelson 2019). They are considered "inspirational experts"(Sundermann and Raabe 2019, 279) and "trusted advisors" (Scheunert et al. 2018, 75; own translation) with an identification value (von Rotz and Tokarski 2020). They have a close relationship with their followers (e.g., adolescents; Enke and Borchers 2018) and create an "illusion of a face to face relationship" (von Rotz and Tokarski 2020, 427).

"Many organizations have identified social media influencers (SMIs) as relevant intermediaries, most notably because they provide access to and might even influence hard-to-reach stakeholders, e.g., teenage and young adult consumers" (Enke and Borchers 2019a, 261; see also Borchers 2019).

Influencers are online opinion leaders, defined as individuals with an influence on others' decision making and behaviors (Casalóa, Flavián, and Ibáñez-Sánchez 2018; Godey et al. 2016; Rogers and Cartano 1962). In the context of influencer marketing, these individuals are sought out by companies or nonprofit organizations (NPOs) to increase the reach of their products or to attract more attention to the companies or NPOs in general (Enke and Borchers 2018; Krömer, Borchers, and Enke 2018; Lou and Yuan 2019). They have different roles, such as content creators, multipliers, moderators, and protagonists, and act in their clients' interests (Enke and Borchers 2019a, 265). Influencers recommend products, services, or companies and specify what is good or bad, updated or outdated. For these recommendations, they often use a selfpresentation as natural as possible (Wellman et al. 2020). Furthermore, they pursue a commercial interest, on the one hand, and want to (further) increase their own reach, on the other (Casalóa, Flavián, and Ibáñez-Sánchez 2018). In order to achieve these goals, they pursue a target-group-oriented approach and create self-presentation based on the expectations of the target group (e.g., adolescents) and the advertising partner (von Rotz and Tokarski 2020).

This form of marketing uses influencers as testimonials. They show commercials with themselves on their Instagram profiles in order to post paid advertising messages and recommend products. Although advertising messages should be labeled as such (e.g., commitment to disclosure; Enke and Borchers 2019b), this is not always the case since the casual showing, mentioning, or favoring of products or brands in their posts can also have an influential persuasive effect. Cathy Hummels, one widereaching and popular influencer among adolescents in Germany, obtained the right to waive the labeling of advertising in front of a court in 2020 (Handel 2020). However, the jurisdiction in Germany is currently as unclear in this regard (when it must be labeled or not) as to the question of where advertising begins (e.g. Brecht 2019). In other cases, influencers were obliged to identify all advertising posts as such. Pamela 
Reif lost a court case in 2020 and is required to continue labeling all her advertisements on Instagram (Kranich 2020). A glance at her profile, on which she advertises underwear and sportswear, for example, shows that she does not always implement this. In this case, the persuasive communication intention is not apparent at first glance (Scheunert et al. 2018), which may make it difficult to distinguish between advertising and content due to the authentic presentation and casual mentioning of the products. Consequently, Instagram's appeal for advertisers is not surprising; it offers them the opportunity to reach adolescents as young consumers in an environment where they are heavily involved. Additionally, the advertising, disguised as product recommendations, comes from someone who adolescents know, trust, and admire to a certain extent (de Veirman, Hudders, and Nelson 2019).

Adolescents orient their self-presentation toward the expectations of referent others, who could also be role models for this content (von Rotz and Tokarski 2020; Yau and Reich 2018). So far, research has focused primarily on groups close to adolescents, such as parents or friends (Arnett 2007; Clark 2011; Hurrelmann and Bauer 2018; Nimrod, Elias, and Lemish 2019; Roedder John 1999; Yau and Reich 2018), or on the link between influencer content and brand expectations (de Veirman, Hudders, and Nelson 2019). If adolescents actively follow influencers' accounts on Instagram, then it is likely that influencers could also be benchmarks for the youths' self-presentation (de Veirman, Hudders, and Nelson 2019; Geber and Hefner 2019; van Dam and van Reijmersdal 2019). RQ 2 addresses this assumption:

RQ 2: Do adolescents use influencers as benchmarks for their self-presentation on Instagram?

\subsection{Advertising Literacy}

"Advertising literacy is generally defined as conceptual knowledge of advertising" (Rozendaal et al. 2011, 335). Following this definition, a person is advertising literate if he or she is able to recognize advertising and its source, as well as understand the target audience, advertising's selling and persuasive intent and tactics, and finally, advertising's bias (Rozendaal et al. 2011, 335). However, Rozendaal et al. (2011) emphasize that knowledge alone does not distinguish advertising literacy and that the use of knowledge and attitude is also a relevant component. They therefore propose a tripartite division of "advertising-related knowledge" (conceptual advertising literacy), the "actual use of advertising knowledge while being exposed to advertising" (advertising literacy performance), and "attitudinal advertising literacy" (Rozendaal et al. 2011, 344). The first dimension addresses the perception of advertising and understanding as the cognitive component (Huders, Cauberghe, and Panic 2016; Kröger 2018), dimension two focuses on the application of knowledge, and dimension three 
highlights the attitude toward advertising (Rozendaal et al. 2011, 346; Rozendaal, Opree, and Buijzen 2016, 74). The latter two dimensions cover affective components of advertising literacy (Hudders, Cauberghe, and Panic 2016). Affective advertising literacy manifests itself if "negative feelings of dislike and disbelief are aroused upon confrontation with advertising" (Hudders, Cauberghe, and Panic 2016, 910; Rozendaal, Opree, and Buijzen 2016).

Following this tripartite conceptualization of advertising literacy (Rozendaal et al. 2011), Hudders et al. $(2017,335)$ differentiate between dispositional and situational advertising literacy, and thus the recognition of advertising, as well as moral and affective abilities. Situational advertising literacy concentrates on the situational application of dispositional skills and the critical reflection of the perceived advertising message and should trigger one's own dispositional skills. This distinction between dispositional and situational skills helps to explain possible differences with regard to knowledge, evaluation, and use because advertising literacy requires the ability not only to recognize advertising but also to evaluate and to act according to that knowledge (Hudders and Cauberghe 2018; Rozendaal et al. 2011; Rozendaal, Opree, and Buijzen 2016).

By considering the use of and attitude toward advertising content, the definition of advertising literacy "becomes more in line with the original meaning of the term literacy, which encompasses more than just the ability to identify and understand messages" (Rozendaal et al. 2011, 345), and similarities to the media literacy definition become apparent. Media literacy consists of knowledge, evaluation, and action (Pfaff-Rüdiger and Riesmeyer 2016; Schorb 2005). An adolescent is considered advertising literate if he or she recognizes advertising messages (a knowledge of advertising, Instagram commercial characteristics, the identification of paid content among that of an organic nature, and influencers' self-presentation as a possibly staged and commercial-interest-driven activity; cognitive dimension), evaluates them (positive, neutral, or negative evaluation as a critical reflection of the consumed content and the perception of influencers' self-presentation; attitudinal dimension), and uses this knowledge and evaluation when confronted with advertising content (acting upon one's own self-presentation; adaptation of one's consumer behavior; performance dimension); as a result, these dimensions are closely linked to one another and sometimes overlap (Pfaff-Rüdiger and Riesmeyer 2016).

Previous studies have shown that advertising literacy develops in childhood and adolescence and is influenced by the social environment and parental mediation strategies (e.g., de Veirman, Hudders, and Nelson 2019; Friestad and Wright 1994; Hudders et al. 2017; Kröger 2018; Lou, Kim, and Xie 2020; Riesmeyer, Abel, and Großmann 2019; Roedder John 1999; Rozendaal, Buijzen, and Valkenburg 2011). Although there are some studies linking hybrid advertising to recognition, persuasion, and purchase intention among adolescents (de Jans and Cauberghe 2018; van Reijmersal 
and Boerman 2016; Verhellen and Dens 2014), a more in-depth extension of this concept toward influencers is needed as they build a bridge between entertainment and advertising. Furthermore, identity formation is a central development task in adolescence (Erikson 1959, 1968), within which Instagram is a place to experiment with one's own identity and try out different ways of presenting it. The identity formation process occurs in different social settings and is influenced by relevant others (Maccoby 1980; Yau and Reich 2018), for example, influencers. They can be role models for adolescents' self-presentation (von Rotz and Tokarski 2020). To date, only a few studies have focused on social media influencers (de Veirman, Hudders, and Nelson 2018) and adolescents at the reflective stage (11-16 years old; Roedder John 1999). RQ 3 therefore emphasizes adolescents' advertising literacy and examines the extent to which they are able to perceive and evaluate influencers' advertising content and self-presentation:

$R Q$ 3: Are adolescents able to recognize influencers' advertising content and selfpresentation, evaluate them, and act according to their own advertising knowledge?

\section{Method}

To answer these RQs, a qualitative research design was chosen because it is often difficult for adolescents to express themselves regarding complex perceptions or to gauge approval or rejection. Due to its openness, a qualitative approach offers them more time and space to reflect on perceptions and actions. Furthermore, this methodological design was selected because it is well-suited to examining mindsets, opinions, and behaviors (Creswell 2007; Flick 2018; Kvale and Brinkman 2009; Mason 2018). Therefore, in-depth interviews were combined with think-aloud protocols to encourage adolescents to speak about their self-presentation, that of influencers, and their own advertising literacy.

Interview guide. The development of the interview guide was based on the theoretical assumptions described above and consisted of four sections:

- Everyday life: characteristics of everyday life, social media use in general, Instagram use in particular (e.g., duration, importance in everyday life, numbers and kinds of followers)

- Knowledge and reflection on self-presentation: background knowledge about posting on Instagram (e.g., image processing, publication time, range, hashtags), the classification and evaluation of viewed content, the characterization of adolescents' self-presentation (rules, their publishing strategies, their orientation toward others, e.g., influencers, peers) 
- Followed influencers: the characterization of the accounts they followed (e.g., kinds of accounts, such as sports, music, arts; reasons for following these accounts), influence on their consumer behavior

- Advertising literacy: knowledge and evaluation of advertising on Instagram (e.g., the perception and appraisal of such content), the use of knowledge (action, orientation toward influencers, the adaptation of consumer behavior)

Based on the four sections, nineteen main questions (and up to four follow-up questions) were developed. The interview guide was used flexibly. If answers to a specific follow-up question had already been given, the question was omitted.

Think-aloud. To encourage adolescents to articulate their advertising literacy, their ideas regarding the presentations, and their perceptions of influencers, a primary task was integrated into the interviews. The adolescents were shown the Instagram account of 'matiamubysofia', a female German model and influencer. Her account was chosen because of her reach (about 526k followers in September 2020); her thematic content, which is closely related to adolescents' everyday lives (e.g., beauty, sports, lifestyle; de Veirman, Hudders, and Nelson 2019); and her function as an inspiration and role model among adolescents (von Rotz and Tokarski 2020). Adolescents' presumed acceptance and positive, neutral, or negative evaluations were tested in the first phase of the interviews through the think-aloud approach, which consisted of two steps. First, the adolescents were asked to look at the profile and describe their impressions in general. They were then presented with a post with advertising content (as advertising labeled as product placement for a perfume implemented in a post for Mother's Day) and were asked to speak freely and without any instructions about what they saw, whether they recognized the post's commercial interests, and how they evaluated it overall. This method has the advantage of making the participants react specifically to what is shown, depending on the situation, thus creating a real-life scenario, which eliminates unwanted distortion effects (Bilandzic 2017). Through think-aloud protocol, this study gained detailed insights into adolescents' perceptions and evaluation processes with regard to Instagram usage.

Sample. In total, 32 interviews with adolescents were conducted during the summer of 2018. They were recruited through a purposive-sampling approach to cover as broad a spectrum of sociodemographic backgrounds as possible (age, gender, and school type; Lindlof and Taylor 2011; Ritchie et al. 2014). While this selection strategy worked very well in terms of the type of school (50 percent lower secondary school and secondary school, 50 percent grammar school) and age (14 years old: 6 adolescents, 15 years old: 10 adolescents, 16 years old: 11 adolescents, 17 years old: 5 adolescents; $M=15.5$ ), it was not possible to achieve an equal distribution of gender. The interviewees consisted of 11 boys and 21 girls. All adolescents came from Munich or neighborhood communities; they were interviewed in their social environments (e.g., at home, at school). 
Interviews. Under a research project at LMU Munich, this study's authors conducted audio-recorded, face-to-face interviews together with 14 bachelor's degree students; these interviews were subsequently transcribed and anonymized to protect the adolescents' privacy. Before the interviews, the adolescents and their parents gave written consent. The interviews lasted an average of 35 minutes each (2165 minutes).

Analysis. All the interviews were independently analyzed by the authors using qualitative content analysis (Flick 2018). Thereby, a theory-driven approach was used. First, all the transcripts were read several times, and relevant interview excerpts were assigned to the categories of everyday life (i. e., typical Instagram use), knowledge and reflection on self-presentation (i. e., kinds of and typical characteristics of their own self-presentation via Instagram), followed or admired influencers (i. e., influencers' functions, such as role models, inspirations), and advertising literacy (i. e., knowledge about Instagram as a platform for pursuing commercial and persuasive interests, the recognition of advertising labeling, the evaluation of influencers' self-presentation, the application of knowledge). Based on these categories, line-by-line coding of each transcript was conducted, and the codes were organized into a table with which direct comparisons of extracted aspects could be made to identify common topics, similarities, and differences among the adolescents in terms of categories. Afterward, the codes were condensed and generalized to extract their central meanings and, in the course of this, five types of adolescents' self-presentation on Instagram, which differed regarding their perception of influencers and their advertising literacy, were identified.

\section{Results}

\subsection{Adolescents' Self-Presentation on Instagram}

Regarding the self-presentation of the 32 adolescents, two positions became clear: they stressed the protection of their privacy and the limits of self-presentation on Instagram. They did not show their private and intimate moments. Many of the adolescents explained that they did not post images that were too personal or revealing, let alone nude images. Bikini pictures were rarely shown and if so, on accounts to which only close friends had access. Only Paula (aged 17) had no qualms about showing a little more skin on her public account "because you wear a bikini to be seen". The majority of the adolescents did not want to show photos that could be problematic later when looking for a job. This attitude was based on their knowledge that the internet forgets nothing: 
"It's just such a big deal, really. It's not only on Instagram, but it's everywhere when you upload it. Anyone can see it. If I want to get a job, I should not post party pictures now because they will be there forever" (Nils, aged 16).

The adolescents mostly posted photos with friends, from their vacations, and of memorable moments. They rarely mentioned selfies and were more likely to be seen in photos that others had taken. Despite these similarities, the form of adolescents' self-presentation varied greatly and was manifest in five types.

\section{Type 1: Staged Self-Presentation}

Eight adolescents (six girls, two boys) primarily valued the perfect online staging of themselves. They focused on aesthetics for the sole purpose of "looking good" (Bastian, aged 16). It was important to them to put themselves in the limelight and show only their most attractive side - even if it did not correspond with reality or showed only part of it. This form of self-presentation was complex. All adolescents in this group posed to take particularly beautiful pictures and edited them afterwards to show perfectly staged impressions of their own lives. The editing sometimes went beyond the optimization of colors. For example, Paula (aged 17) used an app with which she could retouch photos. To take the perfect picture, they sometimes went to great lengths, such as organizing photo shoots with friends (e.g., Bastian, aged 16) or integrating these shoots into other social gatherings (e.g., Cora, aged 15). Only some photos were taken spontaneously, but even those were not free from ulterior motives, and the adolescents consciously tried to put themselves in the limelight (e.g., Rita, aged 16). First, the subject for Instagram was chosen, and then the photo was taken:

"When you go on a city trip, you go to a popular, beautiful place, so you can take a nice picture there and post it. Sometimes they are snapshots, but I think overall, they are more often posed pictures" (Hannah, aged 16).

It was noticeable that the adolescents belonging to this type identified their profiles as being close to reality, even if they talked about staged self-presentation at the same time, which highlighted a discrepancy between their knowledge and actions.

"The picture should actually reflect reality. But when you take photos, you say 'now stand like this' or 'now laugh like this'. It's always a bit of a pose. But basically, it's true to reality" (Hannah, aged 16).

However, others were more aware of the staging. They knew that a photo could provoke negative reactions from others, and they wanted to avoid these sanctions by staging their self-presentation. 
The adolescents belonging to this type either had a public or a private account where they accepted people whom they did not know. The goal of presenting themselves in front of a broader and anonymous public seemed to explain the effort put into creating and editing the pictures. Among the adolescents, there were both insecure and self-confident boys and girls. This form of self-expression was attractive for both groups because those who lacked self-assurance could create pictures that lived up to their self-expectations through image editing and good poses. Combined with likes and positive comments, this, in turn, could boost self-confidence without the need for direct interactions with other people. This form of self-expression also offered confident adolescents the opportunity to show themselves in ways that corresponded with their own imaginations or came very close to their desires.

\section{Type 2: Natural, authentic self-presentation}

The thirteen adolescents (eight girls, five boys) in the type-2 group were a contrast to those in the type-1 group. They preferred authentic and aesthetically appealing self-presentation:

"It should not be unreal and not be posed that way. The picture should have something to do with me, but I don't want to post pictures in which I look totally ugly" (Anja, aged 17).

This quote illustrates the demands of self-expression of this type. For these adolescents, it was important to not pretend and instead to post photos that were close to their own realities in order to achieve a certain degree of authenticity. At the same time, this type expressed the desire to feel comfortable with their self-presentation on Instagram. It was interesting to see how the aesthetically authentic individuals justified their desire to reflect reality; for Franziska (aged 15), it seemed natural to remain true to herself - even online. Anton (aged 16) explained that his followers knew him and how he acted in real life. Adjusting his personality or changing his appearance therefore seemed senseless.

Their claims in terms of natural, authentic self-presentation also became clear in regard to their selection of images and posting behavior. The adolescents belonging to this type hardly or never edited their images. If they did, they usually used filters or editing options provided by Instagram itself, but in contrast to the type-1 group, they did not use special editing programs. For example, colors or contrasts were changed to improve the image quality but not to change their own appearance. Noticeably, the adolescents of this type, as opposed to those in the type-1 group, did not take pictures specifically for Instagram. These pictures mostly already existed and were then selected and published:

"I'll look at the pictures afterwards, but I do not plan when and how to take a picture for Instagram" (Klara, aged 16). 
All adolescents belonging to this type had private accounts. It was important for them to be able to control who saw the pictures. They appeared self-confident and partly perceived themselves as such: "I am not shy, not at all" (Anja, aged 17). A connection to self-expression can be drawn; it requires a certain degree of selfconfidence to accept one's identity and share it with others on Instagram. Potential uncertainties seemed to be compensated for by the fact that the adolescents chose pictures they felt most comfortable with. Instagram per se had little value for this type. This finding was reflected in their Instagram use. With two exceptions, the adolescents indicated that they rarely posted anything or had long intervals between posts; instead, they mostly looked at other people's pictures, only occasionally liking or sharing content.

\section{Type 3: Covert self-presentation}

The type-3 group consisted of two girls who uploaded pictures but were careful not to show their faces despite their private profiles. Privacy concerns were central for both girls. Consequently, they reflected on how to show themselves online and opted for private but natural self-presentation. However, showing their faces made them uncomfortable. For example, Nina (aged 14) showed herself in a way that "you can see me from behind or from the side". The two girls also followed what others posted but seldom posted their own pictures. Nina's Instagram user motivation was striking; she did so because it was normal in her circle of friends and had been set as a rule. She had succumbed to the perceived peer pressure to have an Instagram account:

"Everybody always said how great it was and that it was the latest trend. I found it stupid that everyone laughed at me because I didn't have Instagram. I didn't really want to download it, but then I did it because everybody has it" (Nina, aged 14).

\section{Type 4: Changed self-presentation}

Two boys changed their self-presentation (type 4).

"In the past, I posted a lot, but a year ago, I deleted everything, and now I honestly only use Instagram to stalk other people" (Gustav, aged 16).

He and Carsten (aged 15) had begun using Instagram to observe and keep in touch with their friends. Their earlier self-presentation corresponded more with the type-1 group and was characterized by staging. The changes could be explained by the two boys' development during adolescence and thus the developmental tasks to be fulfilled. Carsten indicated that he no longer liked his previous pictures because his appearance and thus his self-perception had changed.

"Back then, I was a bit fat. Therefore, I deleted them. But at some point, I will be back and more active than today" (Carsten, aged 15). 
His insecurity about his appearance and its effect on others led to his changed self-presentation - in this case, a much more passive one than before. Gustav found it difficult to express why he had changed his self-presentation. He believed that over time, his tastes and thus his ideas regarding successful and appropriate self-presentation had changed.

\section{Type 5: Two-sided self-presentation}

The two-sided self-presentation group (type 5) corresponded to a combination of the previous variants. In this type, five girls and two boys each had two or more accounts on Instagram. They managed these accounts alone or together with friends to satisfy their need for self-expression. They had chosen a private account for unadulterated, natural self-presentation, which corresponded with that of the type-2 group. For example, on her private account, Mia (aged 15) posted "trash pictures", which only her close friends were allowed to see. More pictures were usually posted on this account than on her second, public account. For this reason, adolescents called the private account a "spam account" (Lilli, aged 14). Thus, not only did the mode of self-expression vary but also the content and the circle of recipients.

"In the 'private, private [account],' I post more things or even funny things with friends, grimaces, or intimate things" (Diana, aged 15).

However, some adolescents also said that with this private profile, they were pursuing not only authentic but also aesthetic aspirations. Perhaps they had internalized Instagram's perceived logic of showing themselves to be as perfect as possible and could not discard this idea in their supposedly natural self-presentation.

In addition to their private accounts, they presented themselves in a (more) staged manner on their public accounts (corresponding with the type-1 group), where the photos were edited without exception. At the same time, the photos were specially created with the aim of publishing them. In some cases, photo shoots among friends were organized for this purpose.

"I have a public [profile] for sport. There are a lot of people following me who I don't even know. And that bothered me a bit sometimes because I couldn't post everything I wanted to. I didn't want everyone to see it. So, I have another one [a profile] where I only follow people that I know. And there, I post all kinds of things from my normal life. The other one is to present your best side." (Nils, aged 16).

Influences of age, gender, and school type

Neither age (with two exceptions), gender, nor school type influenced which form of self-presentation adolescents chose. Due to the sample composition, the interviewed boys and girls had a small age range (14-17 years). Staged, natural-authentic 
self-presenters, and adolescents with two profiles can be found within the entire age range. Only types 3 and 4 (both with smaller populations) did not adhere to this pattern: the adolescents were of the same age or differed by only one year. This also applied to gender: types 1,2 , and 5 included both boys and girls, while type $3 \mathrm{com}$ prised only girls, and type 4 consisted of only boys. These findings may be explained by the fact that the insecure girls (type 3 ) opted for an active but covert variant of self-presentation, which was based less on their bodies than on memorable moments in their lives. The boys (type 4) compensated for their perceived insecurity by changing their self-presentation. Moreover, all types of schools were included in all five types in equal parts, so formal education had no influence on how the adolescents presented themselves on Instagram.

However, types 4 and 5 demonstrated the importance of the developmental stage in terms of self-presentation. If their self-perceptions changed during the course of identity formation as a developmental task (Havighurst 1972; Hurrelmann 1990; Hurrelmann and Bauer 2018), then they either changed their profiles (type 4) to show as little of themselves as possible or each used two profiles to create a space where they could present themselves and conform with potential expectations. These expectations that they set for themselves were influenced by referent others, such as peers. The fact that peers were relevant to self-presentation became clear in types 3 and 5. Peers set the use of Instagram as a rule (type 3 ) and were so important for self-presentation that accounts were shared with them in order to find a place for natural, non-staged self-presentation (type 5). Only these friends could see how the adolescents perceived and wanted to show themselves.

\subsection{Influencers - Benchmarks for Adolescent Self-Presentation}

RQ 2 focused on influencers' impact on adolescents' self-presentation. Influencers were important benchmarks for almost all the interviewed adolescents, all of whom followed one or more influencers on Instagram and were inspired by their self-presentation. Their self-marketing strategies seemed to appeal to the majority of the interviewed adolescents. They followed accounts that posted pictures concerning various topics related to their everyday lives and interests, such as sports, entertainment, and lifestyle; were aware of certain trends on Instagram set by influencers; and had the appropriate background knowledge regarding special poses, selfies, and hashtags, as well as captions, to identify and evaluate influencers' posting behavior. The adolescents were able to name variants of image processing, which influencers use to present themselves in a correspondingly positive, authentic light, even if they did not use them (especially type 2 ). 
Besides these commonalities, there were differences among the above-mentioned types with regard to their evaluation of influencers' self-presentation and their orientations toward the perceived self-presentation of influencers. The adolescents' evaluations were strongly influenced by their personal tastes. In particular, the type-2 group (natural, authentic self-presentation) criticized the influencers' presentations as being too placed, too strongly processed, and too associated with personal moments. Gloria (aged 17) summed up this criticism of the non-authentic, "posed" pictures as follows:

"Sometimes, I think 'this is already very staged'. Staged pictures that should look nonstaged" (Gloria, aged 17).

This type argued that influencers combined their personal moments with advertising messages (e.g., as shown in the primary task when posting a picture for Mother's Day and advertising perfume at the same time).

"She mixes something personal with product placement, which can be done, but it doesn't have to be. It is just somehow deceitful” (Jonas, aged 16).

Within a broader outlook, this indicates a high awareness of not only influencers' self-presentation but also commercial intent and thus can be interpreted as being advertising literate. Furthermore, it became clear that the type-2 group set the standard of authenticity not only for themselves but also for others. They attached importance to the fact that pictures should not be distorted but instead be as realistic as possible. For example, Anton (aged 16) explained that he only liked influencers who seemed real to him. Accordingly, it would seem logical that these adolescents show a critical attitude toward influencers. It is important for influencers' credibility that they present themselves realistically. This could then lead to a more positive assessment by type- 2 adolescents. Influencers were not role models for these adolescents' own self-presentation. Although they followed certain influencers, they used this as a way to see behind the scenes because they were interested in the influencers' personal lives and wanted to take part in these.

The assessment of the adolescents who staged themselves on Instagram (type 1) revealed them to be mirror images of those in the type-2 group. They rated influencers much more positively and oriented themselves toward the influencers and their presentations. This adolescent type attributed an exemplary function to influencers by creating a feeling of closeness. These adolescents openly admitted their attempts to copy the influencers' behavior and self-presentation.

"They affect me. Not my behavior directly, but my lifestyle. I find them just cool and try to copy them. Not in the extreme sense but so that you can see that these people influence me" (Bastian, aged 16). 
Many adolescents praised the pictures above all for being beautiful and of a high quality. What the type-2 group was rather reluctant to do seemed to please type-1 adolescents, who accepted the staging and partial deviation from reality, as their focus was ultimately on the aesthetics of the pictures. Thus, the strong image editing was rarely criticized as this was a strategy that they used themselves and adopted from influencers for their own self-presentation.

"That doesn't really bother me. I think it's cool if you have a nice picture and if the picture looks even nicer because of image editing. It is positive because then, I have something nice to look at" (Bastian, aged 16).

Again, the adolescents are able to identify certain strategies and utilize them for themselves.

The adolescents who regarded the protection of their privacy as important (type 3) had a negative opinion about influencers, who were not considered to be role models by this type. Therefore, the two girls belonging to this type did not orient their self-presentation toward that of the influencers. This was possibly related to their cautious stance regarding Instagram. In contrast, those who had changed their Instagram use (type 4) held a more positive opinion about influencers. They even oriented themselves toward influencers. This is particularly interesting, given that their previous Instagram profiles (before they deleted all the images) were more in keeping with the self-presentation of those belonging to type 1, who preferred a more positive staging of the self and evaluated influencers. Although their self-presentation had changed, they remained true to their attitude toward influencers.

Finally, the adolescents with two Instagram accounts (type 5) were ambiguous in their assessment, which nonetheless seemed to be consistent with their different claims regarding self-expression and corresponded to their self-presentation. Their assessment depended on which form of presentation was more important to them: the staging (more positive assessment) or authenticity (more negative assessment). However, this case largely confirmed the observation that those who perceived influencers as role models and as being likeable were generally more positive toward them than those who did not feel any sympathy, observe similarities, or accept the influencers' role model function. Correspondingly, depending on the profile where they published a picture, they oriented themselves more or less strongly toward influencers' self-presentation.

\subsection{Advertising Literacy}

RQ 3 focused on the adolescents' advertising literacy and thus their ability to recognize and evaluate the advertising content presented on the influencers' Instagram accounts as well as to use this knowledge for their own self-presentation. These 
results are strongly intertwined with the perception of influencers' self-presentation (chapter 4.2), because the relevance adolescents attributed to influencers regarding their own self-presentation depended on their evaluation of influencers' self-presentation in general. In other words, the ability and willingness to identify influencers' self-presentation (organic and commercial) and its evaluation seem to be linked with the adolescents' own self-presentation. With one exception, they recognized the advertising character of the presented primary task, were able to classify it as a paid product placement, and mentioned that influencers pursued a commercial interest. Only Rosa (aged 15) could not recognize the advertising background of the primary task, even after being given a hint. Instead, she thought that the post was a personal, non-commercial recommendation. All the others were not guided by the style of the post, but referred spontaneously and without specific guidance to its advertising character and recognized the post's advertising label although the product placement was included in a, in terms of her channel feed, natural looking picture and with a fairly emotional caption about Mother's Day. They knew about the commercial mechanisms Instagram is based on and its function as not just a social network site (e.g., to enable interactions with friends) but also as a platform that displays advertising and that influencers use to generate income. Knowledge of advertising on Instagram as well as its characteristics seemed pronounced among all the adolescents interviewed. They were capable of identifying the persuasive and commercial intent within the presented content and had mastered the cognitive dimension of advertising literacy.

As described in section 2.3, advertising literacy also consists of the evaluation of advertising content (and influencers' self-presentation; attitudinal dimension). The interviewed adolescents possessed this dimension of advertising literacy. They were able to articulate a reflective assessment of the primary task and also justify it. They judged the presented influencer and her content, as well as the product placement, both positively and negatively. The evaluation made in each case was predominantly in line with the adolescents' self-presentation and their demands and requirements regarding their own and influencers' self-presentation on Instagram - for example, type- 1 and type- 4 self-presenters expect an aesthetically pleasing, professional looking feed and evaluated the presentation of the shown influencer post positively. In contrast, type- 2 and type- 3 adolescents assessed influencers more negatively and thus chose a different form of self-presentation for themselves. Despite the knowledge that influencers could also pursue a commercial interest with their own profiles, type- 2 adolescents did not accept that and rejected the primary task, whereby the connection between a private, personal moment, such as a gift for Mother's Day, and a commercial interest justified this assessment. Adolescents belonging to the type- 5 group again differed regarding their assessments - depending on which variant of self-presentation was important to them and which they preferred for influencers. 
Finally, advertising literacy comprises the application of knowledge (performance dimension). The main question here is how to apply knowledge about the functioning and mechanisms of advertising messages (e.g., acting as self-presentation; a consumer's adaptation behavior). As explained in chapter 4.2, all the interviewees followed one or more influencers. However, their concrete self-presentation was only partially oriented toward their perceptions regarding influencers' self-presentation and thus on their ability to evaluate the shown content. They did not always use influencers as role models and consciously decided against an adaptation of their perceptions of influencers' self-presentation. Type 2 was much more critical of influencers and applied its cognitive and attitudinal advertising literacy accordingly in its self-presentation. For this type, influencers were not an inspiration or role model. In particular, for those who preferred staged self-presentation, an orientation toward influencers became apparent - their cognitive and attitudinal advertising literacy was pronounced, but these dimensions had not been applied to their own self-presentation.

With regard to the impact on adolescents' consumer preferences, the type-2 group was not affected by influencers to the same extent as the others. However, the adolescents' negative evaluations did not automatically lead to a rejection of the implied advertising message and product. The more negatively evaluating type-2 adolescents sometimes still drew inspiration from influencers and bought an advertised product but indeed less often than those who expressed a more positive attitude toward influencers, such as the type-1 adolescents. The latter's purchase decisions were affected by influencers, and they tried out advertised products (in general as well as the perfume shown in the primary task). If an influencer advertised a product, type-1 adolescents perceived it as 'cool' (Bastian, aged 16) and something they wanted to try and perhaps would not have bought without the influencer's recommendation.

\section{Discussion}

This article analyzes adolescents' self-presentation on Instagram, the role that influencers might play in such content, and adolescents' advertising literacy, defined as the ability to recognize and to evaluate advertising presented by influencers, as well as influencers' self-presentation, and the capacity to act according to their own advertising knowledge. The results show that adolescents differ in the ways that they present themselves and are able to articulate and justify these differences. Five types of self-presentation have been identified (RQ 1). According to Yau and Reich (2018), some adolescents use a staged form of self-presentation to show themselves in a positive way. This form of self-presentation is closely linked to the expectations of referent others; above all, peers are important for this type of presentation (Siibak 
2009). Furthermore, forms of presentation change over time, as Chua and Chang (2016) already noted. Finally, adolescents are able to find their own approaches to self-presentation. On the one hand, they do so by using a non-staged form of selfpresentation, but this can also be influenced by their circles of peers and friends. On the other hand, they use two or more accounts (together with close friends; Yau and Reich 2018). They are thus able to not only orient themselves toward the expectations of referent others but also follow their own paths regarding self-presentation and prioritize their own expectations and demands over those of referent others.

This chosen form of self-presentation is closely linked to the role that influencers play for them (RQ 2). Influencers stage themselves as role models, deal with topics that are closely related to the everyday lives of adolescents, and 'can be regarded as highly popular and admired peers' (de Veirman, Hudders, and Nelson 2019, 12). Due to these characteristics, the interviewed adolescents follow them regularly. However, their visual selves could, but do not have to, orient themselves toward influencers and their self-presentation. Even if referent others are important for self-presentation (Geber and Hefner 2019; Yau and Reich 2018), the findings show that only those adolescents who opt for a staged form are guided by influencers' self-presentation. Influencers are much more often role models for those adolescents. They serve as inspirations and are perceived as sympathetic and close to the adolescents' own world. For the remaining adolescents, influencers are less relevant to their self-presentation. Their attitudes toward influencers' presentations and often highly embellished online appearances is the most critical; furthermore, they orient themselves toward their own demands or the expectations of their friends.

However, this finding does not mean that influencers per se are irrelevant to adolescents. On the contrary, trying out recommended products is also conceded by adolescents who distance themselves from influencers for the sake of self-expression (except type 3). The findings thus confirm the assumptions of de Veirman et al. (2019) because adolescents not only appreciate influencers' recommendations but also trust their advice; if influencers recommend the product, it cannot be that bad.

Based on the dimensions of advertising literacy, the interviewed adolescents can be considered advertising literate in terms of knowledge and evaluation (RQ 3). Even the placement of advertising does not cause them any difficulties. With one exception, they were able to recognize the shown advertising content and evaluate it positively or negatively. However, their use of knowledge differs. Adolescents who prefer a staged self-presentation do not act according to their knowledge and orientate their self-presentation and consumer behavior toward influencers' self-presentation. On the other hand, adolescents with a critical and mostly negative evaluation of influencers are seldom influenced and instead apply their knowledge with regard to their self-presentation. However, sometimes they make their consumer decisions based on the recommendations of influencers but less often than those who express 
a more positive attitude toward influencers. An influence of age on advertising literacy in terms of all three dimensions cannot be confirmed by the available findings (Hudders and Cauberghe 2018; Hudders et al. 2017; Roedder John 1999; Rozendaal, Buijzen, and Valkenburg 2011; Schulze 2012).

Depending on how participants present themselves, they arrive at a positive or a negative assessment of the advertising message. However, this assessment is not always linked to the corresponding action because even those adolescents who had a negative assessment of product placement would buy the product. This finding highlights the need to focus advertising literacy not only on cognitive skills (pure knowledge), but also on evaluation and action (Pfaff-Rüdiger and Riesmeyer 2016; Rozendaal et al. 2011). The distinction between dispositional and situational advertising literacy proposed by Hudders et al. (2017) is helpful in this context. In this way, the application of the cognitive dimension in the confrontation with advertising messages can be grasped - because knowledge alone is not enough. It must be activated and applied in each concrete situation in order to evaluate and, if necessary, reject advertising messages.

Despite the meaningfulness of the findings, this study has three limitations. Although qualitative interviews are suitable for adolescents to reflect on their actions and behaviors, it cannot be ruled out that they present socially desirable answers. By asking second-order questions and creating an impression of the entire interview, this response behavior can be put into perspective but not be completely excluded. Moreover, the sample is small due to the qualitative research design. Under certain circumstances, a larger sample would mean that the two types ( 3 and 4 ) with very small numbers of participants would include more adolescents and thus be more meaningful. Finally, based on the chosen qualitative research design, it is not possible to analyze causal relationships between self-presentation and advertising literacy. Instead, the aim was to identify possible compounds and thus provide an approach for future research. Despite these three limitations, the findings contribute to the current state of research. The typology shows the different ways in which adolescents use Instagram, how this use may change over time, and what they adopt as a guide for self-presentation. Thereby, the importance of one's own expectations for one's self-presentation becomes clear. Future studies could use this typology as a starting point, expand on it, and examine whether it can be transferred to other social media platforms, such as Snapchat or TikTok. Furthermore, one possibility is to extend the age range (younger or adult users) in order to investigate whether self-presentation changes with age since advertising literacy is developed in childhood and adolescence and "is further refined when consumers become experienced" (Hudders and Cauberghe 2018, 207). 


\section{References}

Arnett, Jeffrey Jensen. 2007. «Socialization in Emerging Adulthood». In Handbook of Socialization: Theory and Research, edited by John E. Grusec, and Paul D. Hastings, 208-231. New York: Guildford Press. https://psycnet.apa.org/record/2015-05080-004.

Bilandzic, Helena. 2017. «Lautes Denken». In Qualitative Medienforschung: ein Handbuch, edited by Lothar Mikos, and Claudia Wegener, 2. edition, 362-370. Konstanz: UVK Verlagsgesellschaft $\mathrm{mbH}$.

Borchers Nils S. 2019. "Social Media Influencers in Strategic Communication». International Journal of Strategic Communication 13 (4): 255-260. https://doi.org/10.1080/155311 $8 X .2019 .1634075$.

Boyd, Danah. 2014. It's Complicated: The Social Lives of Networked Teens. New Haven: Yale University Press. https://www.jstor.org/stable/j.ctt5vm5gk.

Brecht, Katharina. 2019. «Warum Instagram-Posts von Influencern nicht automatisch Werbung sind». Horizont. Accessed July 1st, 2021, https://www.horizont.net/marketing/nachrichten/ begruendung-des-vreni-frost-urteils-warum-instagram-posts-von-influencern-nicht-automatisch-werbung-sind-172472.

Casalóa, Luis V., Carlos Flavián, and Sergio Ibáñez-Sánchez. 2020. «Influencers on Instagram: Antecedents and Consequences of Opinion Leadership». Journal of Business Research 117 (September): 510-19. https://doi.org/10.1016/j.jbusres.2018.07.005.

Chua, Trudi Hui Hui, and Leanne Chang. 2016. «Follow me and Like My Beautiful Selfies: Singapore Teenage Girls' Engagement in Self-Presentation and Peer Comparison on Social Media». Computers in Human Behavior 55: 190-197. https://doi.org/10.1016/j.chb.2015.09.011.

Clark, Lynn Schofield. 2011. «Parental Mediation Theory for the Digital Age». Communication Theory 21 (4): 323-343. https://doi.org/10.1111/j.1468-2885.2011.01391.x.

Creswell, John W. 2007. Qualitative Inquiry and Research Design: Choosing Among Five Approaches. Second Edition. Thousand Oaks: SAGE Publications, Inc.

de Jans, Steffi, Veroline Cauberghe, and Liselot Hudders. 2019. «How an Advertising Disclosure Alerts Young Adolescents to Sponsored Vlogs: The Moderating Role of a Peer-Based Advertising Literacy Intervention through an Informational Vlog». Journal of Advertising 47 (4): 309-325. https://doi.org/10.1080/00913367.2018.1539363.

de Veirman, Marijke, Liselot Hudders, and Michelle R. Nelson. 2019. «What Is Influencer Marketing and How Does It Target Children? A Review and Direction for Future Research». Frontiers in Psychology 10: 2685. https://doi.org/10.3389/fpsyg.2019.02685.

Dumas, Tara M., Matthew Maxwell-Smith, Jordan P. Davis, and Paul A. Giuliett. 2017. «Lying or Longing for Likes? Narcissism, Peer Belonging, Loneliness and Normative versus Deceptive Like-Seeking on Instagram in Emerging Adulthood». Computers in Human Behavior 71: 1-10. https://doi.org/10.1016/j.chb.2017.01.037.2edcv.

Elias, Nelly, Lemish Dafna, and Nimrod, Galit. 2019. «Measuring Mediation of Children's Media Use». International Journal of Communication 13: 342-358. https://doi. org/10.1177/1527476420961334. 
Enke, Nadja, and Nils S. Borchers, 2018. «Von den Zielen zur Umsetzung: Planung, Organisation und Evaluation von Influencer-Kommunikation». In Influencer Relations, edited by Annika Schach, and Timo Lommatzsch, 177-200. Wiesbaden: Springer. https://doi.org/10.1007/9783-658-21188-2_12.

Enke, Nadja, and Nils S. Borchers. 2019a. "Social Media Influencers in Strategic Communication: A Conceptual Framework for Strategic Social Media Influencer Communication». International Journal of Strategic Communication 13 (4): 261-277. https://doi.org/10.1080/1553 118X.2019.1620234.

Enke, Nadja, and Nils S. Borchers. 2019b. «Whitepaper Ethikkodex Influencer-Kommunikation». Leipzig: Universität Leipzig. https://bvim.info/ethik/.

Erikson, Erik H. 1959. «Identity and the Life Cycle: Selected papers». Psychological Issues, 1, 1-171. https://psycnet.apa.org/record/1960-02756-001.

Erikson, Erik H. 1968. Identity: Youth and Crisis. New York: W. W. Norton \& Company.

Feierabend, Sabine, Thomas Rathgeb, Hediye Kheredmand, und Stephan Glöckler. 2020. «JIMStudie 2019. Jugend, Information, Medien. Basisuntersuchung zum Medienumgang 12- bis 19-Jähriger». Edited by Medienpädagogischer Forschungsverbund Südwest (mpfs). Medienpädagogischer Forschungsverbund Südwest (LFK, LMK). https://www.mpfs.de/fileadmin/ files/Studien/JIM/2019/JIM_2019.pdf.

Flick, Uwe. 2018. An Introduction to Qualitative Research. Thousand Oaks: SAGE Publications, Inc.

Friestad, Marian, and Peter Wright. 1994. «The Persuasion Knowledge Model: How People Cope with Persuasion Attempts». Journal of Consumer Research, 2: 1-31. https://doi. org/10.1086/209380.

Geber, Sarah, and Dorothee Hefner. 2019. «Social Norms as Communicative Phenomena: A Communication Perspective on the Theory of Normative Social Behavior». Studies in Communication and Media 8(1): 6-28. https://doi.org/10.5771/2192-4007-2019-1-6.

Godey, Bruno, Aikaterini Manthiou, Daniele Pederzoli, Joonas Rokka, Gaetano Aiello, Raffaele Donvito, and Rahul Singh. 2016. «Social Media Marketing Efforts of Luxury Brands: Influence on Brand Equity and Consumer Behavior». Journal of Business Research 69 (12): 5833-5841. https://doi.org/10.1016/j.jbusres.2016.04.181.

Goffman, Erving. 1990. The Presentation of Self in Everyday Life. London: Penguin Books.

Grieve, Rachel. 2017. «Unpacking the Characteristics of Snapchat Users: A Preliminary Investigation and an Agenda for Future Research». Computers in Human Behavior 74: 130-138. https://doi.org/10.1016/j.chb.2017.04.032.

Handel, Stephan. 2020. "Cathy Hummels gewinnt erneut Prozess um Schleichwerbung». Süddeutsche Zeitung. https://www.sueddeutsche.de/muenchen/cathy-hummels-muenchenprozess-schleichwerbung-1.4947877.

Havighurst, Robert J. 1972. Developmental Tasks and Education. New York: David McKay Company. 
Hudders, Liselot, und Veroline Cauberghe. 2018. «The Mediating Role of Advertising Literacy and the Moderating Influence of Parental Mediation on How Children of Different Ages React to Brand Placements». Journal of Consumer Behavior 17: 197-210. https://doi.org/10.1002/ cb.1704.

Hudders, Liselot, Veroline Cauberghe, und Katarina Panic. 2016. «How Advertising Literacy Training Affect Children's Responses to Television Commercials versus Advergames». International Journal of Advertising, 6: 909-931. http://dx.doi.org/10.1080/02650487.2015.1090045.

Hudders, Liselot, Pieter De Pauw, Veroline Cauberghe, Katarina Panic, Brahim Zarouali, und Esther Rozendaal. 2017. "Shedding New Light on How Advertising Literacy Can Affect Children's Processing of Embedded Advertising Formats: A Future Research Agenda». Journal of Advertising 46 (2): 333-349. https://doi.org/10.1080/00913367.2016.1269303.

Hurrelmann, Klaus. 1990. «Parents, Peers, Teachers, and Other Significant Partners in Adolescence». International Journal of Adolescence and Youth 2: 211-236. https://doi.org/10.108 0/02673843.1990.9747679.

Hurrelmann, Klaus, and Ulrich Bauer. 2018. Socialisation During the Life Course. London. https://doi.org/10.4324/9781315144801.

Kranich, Sibylle. 2020. «Influencerin Pamela Reif verliert Prozess um Schleichwerbung». Badische Neueste Nachrichten. Online abrufbar unter https://bnn.de/karlsruhe/influencerinpamela-reif-verliert-prozess-um-schleichwerbung.

Kröger, Sonja. 2018. Kinder als Rezipienten von Online-Werbung. Wiesbaden: Springer. https:// doi.org/10.1007/978-3-658-19714-8.

Krömer, Lisa, Nils S. Borchers, and Nadja Enke. 2018. "Own the Follower: Wie lassen sich Influencer erfolgreich in den eigenen Unternehmenskanal einbinden? Eine Untersuchung anhand der YouTube-Kanäle deutscher Beauty-Unternehmen». In Influencer Relations, edited by Annika Schach, and Timo Lommatzsch, 107-128. Wiesbaden: Springer. https://doi. org/10.1007/978-3-658-21188-2_8.

Kvale, Steinar, and Svend Brinkmann. 2009. InterViews. Learning the Craft of Qualitative Research Interviewing. Thousand Oaks: SAGE Publications, Inc.

Leary, Mark R., and Robin M. Kowalski. 1990. «Impression Management: A Literature Review and Two-Component Model». Psychological Bulletin 107: 34-47. https://doi.org/10.1037/00332909.107.1.34.

Lee, Eunji, Jung-Ah Lee, Jang Ho Moon, and Yongjun Sung. 2015. «Pictures Speak Louder than Words. Motivations for Using Instagram». Cyberpsychology, Behavior and Social Networking 18: 552-556. https://doi.org/10.1089/cyber.2015.0157.

Lindlof, Thomas R., and Brian C. Taylor. 2011. Qualitative Communication Research Methods. London. https://us.sagepub.com/en-us/nam/qualitative-communication-research-methods/book239370.

Livingstone, Sonia, and Ellen Helsper. 2008. «Parental Mediation of Children's Internet Use». Journal of Broadcasting and Electronic Media 4: 581-599. https://doi. org/10.1080/08838150802437396. 
Lou, Chen, and Shupei Yuan. 2019. «Influencer Marketing: How Message Value and Credibility Affect Consumer Trust of Branded Content on Social Media». Journal of Interactive Advertising 19 (1): 58-73. https://doi.org/10.1080/15252019.2018.1533501.

Lou, Chen, Hye Kyung K. Kim, and Quan Xie. 2020. «YouTubers and Instagrammers Are My Best Friends: Explicating the Roles of Influencer Content, Credibility, and Parental Mediation in Adolescents' Parasocial Relationship, Materialism, and Purchase Intentions». Frontiers in Psychology 10: 2567. https://doi.org/10.3389/fpsyg.2019.02567.

Lup, Katerina, Leora Trub, and Lisa Rosenthal. 2015. «Instagram \#Instasad? Exploring Associations Among Instagram Use, Depressive Symptoms, Negative Social Comparison, and Strangers Followed». Cyberpsychology, Behavior, and Social Networking 18: 247-252. https://doi. org/10.1089/cyber.2014.0560.

Maccoby, Eleanor E. 1980. Social Development: Psychological Growth and the Parent-Child Relationship. New York: Harcourt Brace Jovanovich.

Mason, Jennifer. 2018. Qualitative Researching. Thousand Oaks: SAGE Publications, Inc.

Pfaff-Rüdiger, Senta, and Claudia Riesmeyer. 2016. «Moved into Action. Media Literacy as Social Process». Journal of Children and Media 10 (2): 164-172. https://doi.org/10.1080/17482798. 2015.1127838.

Riesmeyer, Claudia, Bernadette Abel, and Annika Großmann. 2019. «The Family Rules. The Influence of Parental Education on Adolescents' Media Literacy». MedienPädagogik: Zeitschrift für Theorie und Praxis der Medienbildung 35 (Media literacy): 74-96. https://doi. org/10.21240/mpaed/35/2019.10.20.X.

Ritchie, Jane, Jane Lewis, Gilliam Elam, Rosalind Tennant, and Nilufer Rhim. 2014. «Designing and Selecting Samples». In Qualitative Research Practice, ed. by Jane Ritchie, Jane Lewis, Carol McNaughton Nicholls, and Rachel Ormston, 111-146. Thousand Oaks: SAGE Publications, Inc.

Roedder John, Deborah. 1999. "Consumer Socialization of Children: A Retrospective Look at Twenty-Five Years of Research». Journal of Consumer Research 26 (3): 183-213. https://doi. org/10.1086/209559.

Rogers, Everett M., and David G. Cartano. 1962. «Methods of Measuring Opinion Leadership». Public Opinion Quarterly 26 (3): 435-441. https://www.jstor.org/stable/2747233.

Rozendaal, Esther, Moniek Buijzen, and Patti Valkenburg. 2011. "Children's Understanding of Advertisers' Persuasive Tactics». International Journal of Advertising 2: 329-350. https://doi. org/10.2501/IJA-30-2-329-350.

Rozendaal, Esther, Matthew A. Lapierre, Eva A. van Reijmersdal, and Moniek Buijzen. 2011. «Reconsidering Advertising Literacy as a Defense Against Advertising Effects». Media Psychology 14: 333-354. https://doi.org/10.1080/15213269.2011.620540.

Rozendaal, Esther, Suzanna J. Opree, and Moniek Buijzen. 2016. «Development and Validation of a Survey Instrument to Measure Children's Advertising Literacy». Media Psychology 19: 72-100. https://doi.org/10.1080/15213269.2014.885843.

Rui, Jian Raymond, and Michael A. Stefanone. 2013. «Strategic Image Management Online. SelfPresentation, Self-Esteem and Social Network Perspectives». Information, Communication \& Society 16: 1286-1305. https://doi.org/10.1080/1369118X.2013.763834. 
Scheunert, Lisette, Daniela Schlütz, Elena Link, and Katharina Emde-Lachmund. 2018. «Inspiration oder Störung? Ein Experiment zur Wirkung von Influencer-Werbung auf Instagram». In Influencer Relations, ed. by Annika Schach, and Timo Lommatzsch, 75-88. Wiesbaden: Springer. https://doi.org/10.1007/978-3-658-21188-2_6.

Schorb, Bernd. 2005. «Medienkompetenz». In Grundbegriffe Medienpädagogik, ed. by Jürgen Hüther, and Bernd Schorb, 257-262. München.

Schulze, Anne. 2012. Internetwerbung und Kinder. Eine Rezeptionsanalyse. Wiesbaden: Springer. https://doi.org/ 10.1007/978-3-658-02830-5.

Sheldon, Pavica, and Katherine Bryant. 2016. «Instagram: Motives for its use and relationship to narcissism and contextual age». Computers in Human Behavior 58: 89-97. https://doi. org/10.1016/j.chb.2015.12.059.

Siibak, Andra. 2009. "Constructing the Self through the Photo Selection - Visual Impression Management on Social Networking Websites». Cyberpsychology: Journal of Psychosocial Research on Cyberspace, 3 (1). https://cyberpsychology.eu/article/view/4218.

Sundermann, Gerrit, and Thorsten Raabe. 2019. «Strategic Communication through Social Media Influencers: Current State of Research and Desiderata». International Journal of Strategic Communication 13 (4): 278-300. https://doi.org/10.1080/1553118X.2019.1618306.

van Dam, Sophia, and Eva A. van Reijmersdal. 2019. «Insights in Adolescents' Advertising Literacy, Perceptions and Responses Regarding Sponsored Influencer Videos and Disclosures». Cyberpsychology Journal of Psychosocial Research on Cyberspace 13(2). https://doi. org/10.5817/ CP2019-2-2.

van Reijmersdal, Eva A., Sophie C. Boerman, Moniek Buijzen, and Esther Rozendaal. 2016. «This Is Advertising! Effects of Disclosing Television Brand Placement on Adolescents». Journal of Youth and Adolescence 46 (2): 328-342. https://doi.org/10.1007/s10964-016-0493-3.

Verhellen, Yann, Caroline Oates, Patrick de Pelsmacker, and Nathalie Dens. 2014. «Children's Responses to Traditional Versus Hybrid Advertising Formats: The Moderating Role of Persuasion Knowledge». Journal of Consumer Policy 37 (2): 235-255. https://doi.org/10.1007/ s10603-014-9257-1.

von Rotz, Jonas, and Kim Oliver Tokarski. 2020. «Social Influencer. Eine Analyse ausgewählter visueller und auditiver Stile erfolgreicher Social Influencer auf YouTube». In Digitale Transformation und Unternehmensführung, ed. by Jochen Schellinger, Kim Oliver Tokarski and Ingrid Kissling-Näf, 407-434. Wiesbaden: Springer. https://doi.org/10.1007/978-3-658-269609_15.

Wellman, Mariah L., Ryan Stoldt, Melissa Tully, and Brian Ekdale. 2020. «Ethics of Authenticity: Social Media Influencers and the Production of Sponsored Content». Journal of Media Ethics 35 (2): 68-82. https://doi.org/10.1080/23736992.2020.1736078.

Yau, Joanna C., and Stephanie M. Reich. 2018. «'It's Just a Lot of Work'. Adolescents' Self-Presentation Norms and Practices on Facebook and Instagram». Journal of Research on Adolescence 29: 196-209. https://doi.org/10.1111/jora.12376. 